\title{
Hypertension Management and Control in Italy: A Real-World Survey in Elderly Patients
}

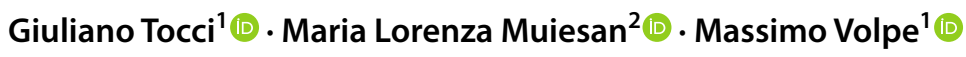

Received: 1 August 2021 / Accepted: 5 August 2021 / Published online: 23 August 2021

(C) Italian Society of Hypertension 2021

Arterial hypertension is a major contributor for cardiovascular morbidity and mortality in elderly, being associated with an increased risk of acute myocardial infarction, stroke, renal disease and congestive heart failure [1,2]. Uncontrolled hypertension is also responsible for development and progression of hypertension-mediated organ damage, that can be frequently documented in aged individuals, at both cardiac, vascular and renal levels, further promoting the risk of hypertension-related cardiovascular events. In particular, it is deeply involved in the pathogenesis of left ventricular hypertrophy and left ventricular systolic and/or diastolic dysfunction, which heavily affect quality of life and event-free survival in elderly people, mostly women [3, 4].

For these reasons, and in view of the progressive ageing of the general population, European guidelines highlighted the importance of achieving effective and sustained control of hypertension in individuals aged 65 years or more, for ameliorating cardiovascular prognosis and improving their quality of life [5]. In these age groups, current guidelines recommended to achieve a systolic blood pressure of $130-139 \mathrm{mmHg}$ and a diastolic blood pressure of $70-79 \mathrm{mmHg}$, if tolerated, independently by the presence of other clinical conditions or comorbidities, such as diabetes, chronic kidney disease, coronary artery disease or stroke [5].

Despite these recommendations, several reports have showed poor rate of control of high blood pressure in the general population of treated and untreated hypertensive patients [6-9]; none of these, however, were focused on elderly populations.

Giuliano Tocci

giuliano.tocci@uniroma1.it

1 Hypertension Unit, Division of Cardiology, Department of Clinical and Molecular Medicine, University of Rome Sapienza, Sant'Andrea Hospital, Rome, Italy

2 Department of Clinical and Experimental Sciences, University of Brescia, and Division of Internal Medicine 2, ASST Spedali Civili, Brescia, Italy
In this issue of High Blood Pressure \& Cardiovascular Prevention, the main findings of an Italian awareness-raising campaign on hypertension, promoted by the Italian FederAnziani, Italian Society of Hypertension (SIIA) and Italian Federation of General Practice (SIMG), are presented [10]. This survey proposes several important items to discuss.

First of all, this is one of the largest survey specifically designed to evaluate the rate of blood pressure control and attitudes for blood pressure lowering drugs prescriptions in individuals aged 65 years or more. The study included 13,196 treated hypertensive patients, predominantly women, with an average age of 73 years, among whom $80 \%$ were treated with monotherapies, about $19 \%$ were on dual combination therapies and only $1 \%$ were on triple combination therapies. In this sample, only $43 \%$ of treated patients were fully adherent to therapy (adherence rate $\geq 80 \%$ ) and about $68 \%$ had controlled hypertension.

In elderly subjects, the most common hypertension phenotype is represented by isolated systolic hypertension, which is defined by systolic blood pressure above 140 $\mathrm{mmHg}$ and diastolic blood pressure below $90 \mathrm{mmHg}$ [11]. This condition is often associated with high pulse pressure (more than $60 \mathrm{mmHg}$ ), a marker of vascular organ damage, and a persistently high rate of major cardiovascular events in hypertensive patients under pharmacological therapies (i.e. the so called "residual risk"). Although several potential explanations have been proposed to interpret this critical issue, poor adherence to prescribed medications is probably the most recognised one.

The study performed by Del Pinto and coworkers reported relatively low proportions of patients fully adherent to prescribed medications and showed a strong relationship between low adherence and pills' burden. In fact, adherence was reduced from about $73 \%$ in those individuals treated with single-pill therapy to about $53 \%$ and $38 \%$ in those treated with two or three pills, respectively. Both rates of adherence to therapy and blood pressure control were higher 
in those patients treated with fixed combination therapies than in those treated with free combinations.

Another interesting finding of the study was the effects of different therapeutic regimens on pulse pressure, which resulted significantly lower in elderly patients treated with dual or triple fixed combination therapies compared to those treated with free formulations. This beneficial effect of fixed combination therapies with two or three antihypertensive agents may have particular relevance in elderly populations, since high pulse pressure is an independent predictor of major cardiovascular outcomes.

Although some intrinsic limitations of the study, mostly related to the not uniform methodological approaches applied for measuring blood pressure levels in different clinical settings, with different devices and different techniques, the results are of particular interest from clinical point of view, since they suggest a potential way improve blood pressure control in elderly patients, by adopting fixed combinations therapies and promoting out-of-office blood pressure assessments. These results are also in line with recent position papers from the Italian Society of Hypertension [14] and the European Society of Hypertension [15], which supported the use of the fixed combination therapies to improve adherence and ameliorate the clinical management of hypertension and hypertension-related cardiovascular diseases, also in elderly patients with high blood pressure.

Overall, the conclusive remarks that can be drawn by this study, as well as by previous similar experiences [12, 13], are that there is no age-limit to provide an effective blood pressure control and promote better cardiovascular protection throughout a more extended use of fixed combination therapies. These strategies can be easily and safely applied also in elderly populations, for reducing the risk of development of hypertension-mediated organ damage and hospitalizations due to cardiovascular diseases.

\section{Declarations}

Funding None.

Conflict of interest Authors have no conflict of interest to disclose with the contents of the present manuscript.

Ethics approval, Consent to participate, Consent for publication, Availability of data and material, Code availability and Authors' contributions Not applicable.
2. Del Pinto R, Ferri C. Hypertension management at older age: an update. High Blood Press Cardiovasc Prev. 2019;26(1):27-36.

3. Muiesan ML, Paini A, Aggiusti C, Bertacchini F, Rosei CA, Salvetti $\mathrm{M}$. Hypertension and organ damage in women. High Blood Press Cardiovasc Prev. 2018;25(3):245-52.

4. Cuspidi C, Rescaldani M, Sala C, Negri F, Grassi G, Mancia G. Prevalence of electrocardiographic left ventricular hypertrophy in human hypertension: an updated review. J Hypertens. 2012;30(11):2066-73.

5. Williams B, Mancia G, Spiering W, Agabiti Rosei E, Azizi M, Burnier M, et al. 2018 ESC/ESH guidelines for the management of arterial hypertension. Eur Heart J. 2018;39(33):3021-104.

6. Volpe M, Tocci G, Trimarco B, Rosei EA, Borghi C, Ambrosioni $\mathrm{E}$, et al. Blood pressure control in Italy: results of recent surveys on hypertension. J Hypertens. 2007;25:7.

7. Tocci G, Presta V, Ferri C, Redon J, Volpe M. Blood pressure targets achievement according to 2018 ESC/ESH guidelines in three european excellence centers for hypertension. High Blood Press Cardiovasc Prev. 2020;27(1):51-9.

8. Tocci G, Nati G, Cricelli C, Parretti D, Lapi F, Ferrucci A, et al. Prevalence and control of hypertension in the general practice in Italy: updated analysis of a large database. J Hum Hypertens. 2017;31(4):258-62.

9. Tocci G, Ferrucci A, Pontremoli R, Ferri C, Rosei EA, Morganti $\mathrm{A}$, et al. Blood pressure levels and control in Italy: comprehensive analysis of clinical data from 2000-2005 and 2005-2011 hypertension surveys. J Hum Hypertens. 2015;29(11):696-701.

10. Del Pinto R, Desideri G, Ferri C, Agabiti Rosei E. Real-world antihypertensive treatment patterns, treatment adherence, and blood pressure control in the elderly: an Italian Awareness-raising Campaign on Hypertension by Senior Italia FederAnziani, the Italian Society of Hypertension and the Italian Federation of General Practitioners. High Blood Press Cardiovasc Prev. 2021. https://doi.org/10.1007/s40292-021-00465-7.

11. Franklin SS, Jacobs MJ, Wong ND, L'Italien GJ, Lapuerta P. Predominance of isolated systolic hypertension among middle-aged and elderly US hypertensives: analysis based on National Health and Nutrition Examination Survey (NHANES) III. Hypertension. 2001;37(3):869-74

12. Torlasco C, Faini A, Makil E, Ferri C, Borghi C, Veglio F, et al. Cardiovascular risk and hypertension control in Italy. Data from the 2015 World Hypertension Day. Int J Cardiol. 2015;2017(243):529-32.

13. Tocci G, Muiesan ML, Parati G, Agabiti Rosei E, Ferri C, Virdis A, et al. Trends in prevalence, awareness, treatment, and control of blood pressure recorded from 2004 to 2014 during world hypertension day in Italy. J Clin Hypertens (Greenwich). 2016;18(6):551-6.

14. Volpe M, Rosei EA, Ambrosioni E, Cottone S, Cuspidi C, Borghi C, et al. 2012 consensus document of the Italian Society of Hypertension (SIIA): strategies to improve blood pressure control in Italy: from global cardiovascular risk stratification to combination therapy. High Blood Press Cardiovasc Prev. 2013;20(1):45-52.

15. Coca A, Agabiti-Rosei E, Cifkova R, Manolis AJ, Redón J, Mancia G. The polypill in cardiovascular prevention: evidence, limitations and perspective - position paper of the European Society of Hypertension. J Hypertens. 2017;35(8):1546-53.

\section{References}

1. Ferri C, Ferri L, Desideri G. Management of hypertension in the elderly and frail elderly. High Blood Press Cardiovasc Prev. 2017;24(1):1-11. 